\title{
Greenhouse gas emissions reduction A theoretical framework and global solution
}

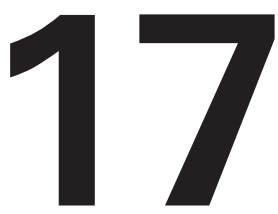

\section{Project Team of the Development Research Centre of the State Council, People's Republic of China}

\section{Introduction}

The Kyoto Protocol, as 'the first game in town', represents significant progress towards reducing global emissions. Its cap-and-trade mechanism and flexible market-based implementation have been valued highly. Meanwhile, there has also been wide criticism (for instance, Nordhaus 2006; EC 2008) of its flaws: 1) small coverage and a lack of effectiveness; 2) countries, especially developing countries, lack incentive to participate; 3) the additionality problem of the Clean Development Mechanism (CDM). To fight effectively against global warming, a more effective post-Kyoto architecture is needed.

Although a variety of alternative proposals aiming to succeed the Kyoto Protocol have their own advantages (Aldy et al. 2003; Aldy and Stavins 2007; Garnaut 2008; Nordhaus 2006, 2008; Stiglitz 2006; Weitzman 1974; Sagar and Kandlikar 1997), each also has its disadvantages. For instance, some require revolutionary changes to establish a framework completely different from the Kyoto Protocol; some are based on the particular interests of certain countries; and some are seen as not sufficiently fair by developing countries, especially by the major emerging emitters.

Although according to the principle of 'common but differentiated responsibilities', developing countries are not required to reduce emissions in the existing Kyoto Protocol, their further involvement is needed in global emissions reduction. Nonetheless, since the rights and responsibilities of each country regarding climate change have not been precisely measured in the unclear term of 'differentiated responsibilities', 
industrialised and developing countries, especially the big global emerging emitters, feel there is an unfair burden sharing and are accordingly critical of one another. Hence, the new international agreement must be built on a solid basis of fairness and must clearly define each country's rights and responsibilities; otherwise the post-Kyoto protocol is not likely to be selfenforcing or effective.

The objective of this chapter is to develop a theoretical framework for allocating each country's emission entitlements and, by establishing a national emissions account (NEA) for each country, to provide a fullcoverage global solution with adequate respect for the rights of developing countries. In section two, we investigate the economic nature of greenhouse gas (GHG) emissions and show how each country's emission (or emissionreduction) behaviour changes once its emission entitlements are clearly defined. In section three, we develop a theoretical framework for how to allocate GHG emission entitlements for each country and provide a NEA-based global solution to emissions reduction. In section four, we use hypothetical data to demonstrate how to establish NEAs for each country and present some findings from the demonstration. In section five, we further explore the implications of the findings and clarify some major issues on climate change. The last section concludes the chapter.

\section{The economic nature of greenhouse gas emissions}

The economic nature of GHG emissions is determined by their natural or technical characteristics. First, due to the mobility of the atmosphere, no matter how much an individual country emits, the harm those emissions do is borne by everyone on Earth. Second, the harm of GHG emissions lasts for hundreds of years due to their long lifetime in the atmosphere. For instance, over the course of a century, although half of the carbon dioxide emitted in any one year will be removed, about 20 per cent of it will remain in the atmosphere for millennia (Solomon et al. 2007:824). Most of the greenhouse gases accumulated in the atmosphere have been emitted by industrialised countries since the Industrial Revolution. Third, the harm of greenhouse gases is non-rival, which means that the harm suffered by a person will not be alleviated because of more people taking the harm. 
Given current technologies, most production activities need todirectly or indirectly - emit greenhouse gases, although the outputs of units of emissions in different countries vary. Therefore, GHG emissions on one hand impose harm on humans; on the other, they bring benefits to humans. If, however, global greenhouse gases are accumulated in the atmosphere beyond a certain level, their harm will far exceed their benefits. Most scientists agree that global greenhouse gases must be limited in the range of 450 parts per million (PPM) of carbon dioxide equivalent $\left(\mathrm{CO}_{2}-\mathrm{e}\right)$, otherwise the consequences will be disastrous (Metz et al. 2007; Stern 2007; Garnaut 2008). How to get all countries to take coordinated action to lower their emissions is, however, a great challenge. The key is to provide incentives for each country to lower its emissions through clearly defining and enforcing each country's emission entitlements.

Greenhouse gas emissions bring harm and benefits. The benefits are owned exclusively by the emitting countries, but the harm is borne by all people of all countries on Earth. Since the emission entitlements of each country are not clearly defined, each country then has an incentive to emit as much as possible to the common atmosphere to maximise their benefits. Excessive emissions lead to global warming, the so-called 'tragedy of the commons' (Hardin 1968). If emission entitlements could be clearly defined and all countries could emit subject only to their quotas, each country's emissions behaviour would change and the limitations on global emissions would not be topped. The countries that needed greater quotas could purchase them from others.

The question of 'by how much should a country reduce its emissions' is the same question as 'how much is a country entitled to emit'? Like emissions, emissions reduction also has benefits and costs. The major 'benefit' of emissions reduction is that it can reduce the expected losses caused by global warming. The cost of a country's emissions reduction is reflected mainly in its decreasing output or increasing input. Due to the mobility of greenhouse gases, a particular country bears the full costs of emissions reduction itself, while all countries share the benefits. Therefore, no country has sufficient incentive to unilaterally reduce its emissions and all want to be free riders. Consequently, it is difficult to achieve a rational result of global cooperation to reduce emissions.

If a country could exclusively claim all the benefits resulting from its emissions reduction then the optimal strategy for each country would shift from not reducing emissions to reducing emissions. Unfortunately, 
in reality, the extremely high costs and technical limitations prevent a country from claiming the benefits to the other countries resulting from its emissions reduction. If, however, the emission entitlements of all countries could be clearly defined then a country reducing its emissions could 'claim' the benefits through the market; its emission quotas for sale would increase or the amount needing to be purchased would decrease.

Hence, the core of the global emissions reduction problem is really one of how to define or allocate each country's emissions entitlements. The Coase (1960) theorem stresses the importance of clearly defined initial property rights for minimising social costs, but does not provide an answer for how to define the initial GHG emission entitlements. Grossman and Hart (1986) and Hart and Moore (1990) stress that, if there are transaction costs, different ownership structures will lead to different performances and there must be one particular ownership structure that is most efficient. Hence, given a global initial emissions rights allocation, an efficient ex post global real emissions allocation will be achieved through the market. The emissions reduction will occur in the countries with the lowest opportunity costs.

How do we define the initial emissions entitlement of each country? The atmosphere is a typical public resource and, in most cases, Earth's public resources have been 'allocated' on a first-serve principle or have even been obtained through war. Moreover, redefining the distorted historical emissions makes things more complicated. We need therefore to find a fair, objective and simple principle to define or allocate the initial emission entitlements for each country.

\section{A theoretical framework and global solution}

\section{A theoretical framework}

We use Figure 17.1 to show the time horizon of emissions. The definition (or allocation) of emission entitlements includes two periods: the historical period, $\mathrm{T} 0-\mathrm{T} 1$, and the future period, $\mathrm{T} 1-\mathrm{T} 2$. 


\section{Figure 17.1 The time horizon for international emissions rights allocation}



TO

T1

$T 2$

Note: TO could represent the point of the Industrial Revolution or another point. ${ }^{1} T 1$ is the current point and T2 is a point in the future-say, 2050.

The problem of how to define (or allocate) each country's emissions rights can be treated as a problem of preventing a country from imposing extra external harm on the others. No matter how much an individual country emits, the harm from those emissions is borne by everyone on Earth. The GHG emissions of each country cause harm not only to the emitting country, but to all people in all other countries. After the external harms imposed by one another are offset, the over-emitting countries still impose extra harm on others.

The definition of property rights is reciprocal. The emission right can be defined to either the emitter or the victim. Defining each party's property rights is essential for fairness, so the following principle should be adhered to: no country has the right to impose extra external harm on any other country without compensation; or, all countries have the right not to bear extra external harm from any others without compensation. If a country imposes extra external harm on other countries, it should compensate them. Therefore, the emissions level at which no country imposes extra external harm on any other country becomes a benchmark for allocating the initial emission entitlements.

\section{Proposition}

A country does not impose extra external harm on any others if and only if each country's per capita emissions are equal. Accordingly, the equivalent per capita emissions are the benchmark for the allocation of initial emission entitlements. If the real emissions of a country are greater than its initial emission entitlements or the global per capita level, it should pay for its extra emissions, and vice versa. 


\section{Proof}

Since the internal allocation of emission entitlements within a country is not discussed in this chapter, for simplicity, we assume that all people's real emissions within a country are the same and are equal to the per capita real emissions of the country, $e_{i j}$. The population of a country is $N_{i}$, and the world population is $N=\sum N_{i}$, in which $i=1,2 \ldots n$ stands for different countries. $j=1,2$ stands for two different periods: $T O-T 1$ and $T-T 2$. The global per capita accumulated emission during period $j$ is $\overline{e_{j}}=\frac{\sum e_{i j} \cdot N_{i}}{N}$. Since the harm caused by each person's emissions is borne by all people around the world, the total external damage a person causes to all the other people is the function of $e_{i j}(N-1)$. Everyone on Earth suffering the harm from GHG emissions is the function of $\sum_{i=1}^{n} e_{i j} \cdot N_{i}=\bar{e}_{j} \cdot N .^{2}$ Since the proportion of $e_{i j}$ is due to the emissions by each person, the external harm imposed by the others is the function of $\sum^{n} e_{i j} \cdot N_{i}-e_{i j}$. Given the assumption that all people's real emissions within a country are equal, the people within a country do not cause extra harm to each other. Therefore, all the extra external harm caused by a person is the extra external harm to the people of all other countries. In the case without a compensation mechanism, the emissions of a person do not cause any extra external harm to any other countries - if and only if:

\section{Equation 17.1}

$$
e_{i j}(N-1)-\left(\sum_{i=1}^{n} e_{i j} \cdot N_{i}-e_{i j}\right)=0
$$

A country does not impose any extra external damage on any other country, if and only if:

\section{Equation 17.2}

$$
\left[e_{i j}(N-1)\right] \cdot N_{i}-\left[\left(\sum_{i=1}^{n} e_{i j} \cdot N_{i}-e_{i j}\right)\right] \cdot N_{i}=0
$$

Insert $\sum_{i=1}^{n} e_{i j} \cdot N_{i}=\overline{e_{j}} \cdot N$ into Equation 17.2 and we have $e_{i j}=\overline{e_{j}}$. It is the benchmark emission level, satisfying the 'if and only if' condition that 'each country does not impose any extra external harm on any other country'. The benchmark emissions level is the initial emissions entitlement, $e_{i j}^{r}$, which will be allocated to each person of each country. Each country's initial emissions entitlement is: 


\section{Equation 17.3}

$$
e_{i j}^{r}=\overline{e_{j}}
$$

If the real per capita emissions of a country are greater than its per capita initial emission entitlement - namely, $e_{i j}>e_{i j}^{r}$ - or greater than the global per capita emission entitlement-namely, $e_{i j}>\bar{e}_{j}$ - then it means this country has imposed extra external harm on other countries and should compensate the others for its extra emissions, and vice versa. Using $e_{i j}^{t}$ to indicate the per capita extra emissions of a country, $e_{i j}^{t}=e_{i j}-e_{i j}^{r}$. Assuming $p$ is the price of a unit of emissions entitlement in the international emissions market, or the shadow price when an international emissions trading scheme is not in place, the compensation will be $y=p \cdot e_{i j}^{t}$. QED.

The global distribution of per capita emission entitlements of all countries in different periods is $\left[e_{i}^{r}\right]$. It defines the global allocation of emission entitlements of each country according to the principle that 'no country has the right to impose extra external harm on any other country without providing compensation'. The emissions distribution of each country is therefore based on an objective rather than a subjective standard. After the emission entitlements are clearly defined, the emission entitlements trade will select an optimal global real emissions structure with the least social cost $\left[\left(e_{i}^{r}+e_{i}^{t}\right)\right]$. In reality, since it is extremely costly to completely and accurately measure the real amount of emissions, $e_{i j}$, of each country, there is a trade-off between improving the accuracy of measuring and enforcing each country's emission entitlements and reducing transaction costs. There is therefore always a marginal error between the measured real emissions and the real real emissions of each country. Therefore, the situation of $\left(e_{i j}-e_{i j}^{t}\right)-e_{i j}^{r}=\varepsilon_{i j} \neq 0$ is always true. The $\varepsilon_{i j}$ is refereed as the efficient externalities (Cheung 1970).

Hence, to define or allocate each country's initial emissions rights, the per capita principle should be used consistently in: 1) all periods - that is, in both $\mathrm{T} 0-\mathrm{T} 1$ and $\mathrm{T} 1-\mathrm{T} 2$; and 2) all countries, including industrialised and developing countries. 


\section{National emissions account-based global solution}

A country's emissions entitlements are:

\section{Equation 17.4}

$$
E_{i j}{ }^{r}=e_{i j}{ }^{r} \cdot N_{i}=\overline{e_{j}} \cdot N_{i}
$$

If a country's real emissions, $E_{i j}$, are greater than its emission entitlements, $E_{i j}^{r}$, it should purchase emissions quotas, $E_{i j}^{t}$, from other countries.

\section{Equation 17.5}

$$
E_{i j}{ }^{t}=E_{i j}-\overline{e_{j}} \cdot N_{i}
$$

The balance of a country's national emissions account (NEA) is $B_{i j}$ :

\section{Equation 17.6}

$$
B_{i j}=\overline{e_{j}} \cdot N_{i}+E_{i j}{ }^{t}-E_{i j}
$$

According to each country's 1) initial emissions rights (entitlements), $E_{i j}^{r}$; 2) real emissions, $E_{i j}$; 3 ) traded emissions, $E_{i j}^{t}$, in two periods of T0-Tl and $\mathrm{T} 1-\mathrm{T} 2$, we can then establish an NEA for each country.

Each country's total balance on its NEA by T2 is the addition of 1) its emissions balance during T0-T1, and 2) its new emissions quotas allocated during T1-T2 plus its traded quotas. The balance on each country's NEA then exactly represents their 'differentiated responsibilities' to reduce emissions (or their rights to emit). Once all countries' responsibilities are clearly defined, an effective international and national approach can be developed. The NEA-based global solution includes three steps.

\section{Step 1}

Each country's emissions rights during T0-Tl must be defined according to the per capita principle. We can then turn the unclear 'historic responsibilities' of the over-emitting countries into clear NEA deficits, and surpluses for others. Since the traded emission is zero and emission costs are not included in the price of traded goods during $\mathrm{T} 0-\mathrm{T} 1$, embedded emissions, in theory, need to be counted as the real emissions of the importing countries - although it is impractical to measure this. 


\section{Step 2}

The future global emission amounts during $\mathrm{T} 1-\mathrm{T} 2$ must be scientifically set and then the emissions quotas allocated among all countries according to the per capita principle. Each country's new emissions quotas during T1-T2, plus the NEA balance during T0-T1 are its total emissions caps by $\mathrm{T} 2$. Since emissions quotas can be traded and emission costs will eventually be reflected in the price of traded goods, embedded emissions are no longer a particular problem when we measure each county's real emissions.

\section{Step 3}

An open and compatible solution must be established for the international collaborative mechanism and the domestic emissions reduction approach to incorporate various existing proposals. The various solutions can then coexist and compete with each other in the NEA framework.

\section{At the international level}

Any existing collaborative mechanisms can be used, as long as their effectiveness is eventually reflected in each country's balances of NEA.

International emissions trading scheme (IETS): changes the balance of the NEA of the emission-trading countries.

Joint implementation (JI): changes the balance of each country's NEA.

Clean Development Mechanism (CDM): increases the NEA balance of industrialised countries and decreases the balance of developing countries side-by-side.

International public emissions reduction fund: the widely proposed public fund can also play its role in the NEA framework. The contribution of a country to the fund increases its balance accordingly, while it reduces the balance of the beneficiary countries.

Technology transfer and research and development: their effectiveness needs to be reflected in the NEA. 


\section{At the national level}

All countries have freedom to choose their domestic approach, as long as they meet their emissions caps by $\mathrm{T} 2$. The countries with emission deficits need to clear their deficits by the target year.

1. A country may adopt an emissions trading scheme (ETS), carbon tax, hybrid system, emissions regulation or any other approach at home.

2. Subject to its total quotas by T2, each country may determine the number of its annual emission permits and make a credible emissions reduction (or emissions) road-map during $\mathrm{T} 1-\mathrm{T} 2$.

\section{A demonstration of how to establish a national emissions account}

\section{A demonstration}

Consider a world consisting of two representative countries: industrial country A and developing country B. Their population, concentrated historical emissions by $\mathrm{Tl}$, current annual emissions at $\mathrm{T} 1$, global emissions and future global emissions quotas during T1-T2 are in Table 17.1. For simplicity, embedded emissions during T0-T1 are assumed to be zero. A country's NEA is established according to its per capita emissions entitlements, real emissions, traded emissions and population. For simplicity, assume the population remains stable during T1-T2.

\section{Table 17.1 Emissions data for each country (hypothetical)} (person, unit)

\begin{tabular}{|c|c|c|c|c|c|c|}
\hline & \multicolumn{2}{|c|}{ Country A } & \multicolumn{2}{|c|}{ Country B } & \multicolumn{2}{|c|}{ World } \\
\hline & Total & $\begin{array}{l}\text { Per } \\
\text { capita }\end{array}$ & Total & $\begin{array}{l}\text { Per } \\
\text { capita }\end{array}$ & Total & Per capita \\
\hline Population at T1 & 200 & - & 400 & - & 600 & - \\
\hline $\begin{array}{l}\text { Current annual net } \\
\text { emissions (at T1) }\end{array}$ & 400 & 2 & 400 & 1 & 800 & 1.33 \\
\hline $\begin{array}{l}\text { Concentrated } \\
\text { historical emissions } \\
\text { during TO-T1 }\end{array}$ & 28000 & 140 & $\begin{array}{c}14 \\
000\end{array}$ & 35 & $\begin{array}{c}42 \\
000\end{array}$ & 70 \\
\hline $\begin{array}{l}\text { Global emissions } \\
\text { quotas during } \mathrm{T} 1-\mathrm{T} 2\end{array}$ & - & - & - & - & $\begin{array}{c}30 \\
000\end{array}$ & 50 \\
\hline
\end{tabular}

- = zero 


\section{Step one: calculating each country's NEA balance during TO-T1}

The global per capita emission during T0-Tl is 70 units of carbon dioxide. For simplicity, we assume the embedded emission is zero. If country A has over-emitted 14000 units of carbon dioxide and its emission deficit is -14 000 units of carbon dioxide by $\mathrm{T} 1$, the emission surplus of country B is 14 000 units of carbon dioxide (Table 17.2).

\section{Table 17.2 National emissions account during T0-T1}

\begin{tabular}{l|c|c|c}
\hline & Country A & Country B & World \\
\hline Emissions entitlements & $\begin{array}{l}200=14000 \\
\text { Real emissions }\end{array}$ & $\begin{array}{l}70 \times 400=28000 \\
42000\end{array}$ \\
\hline Traded emissions & 0 & 14000 & 42000 \\
\hline Balance until T1 & $\begin{array}{c}14000-28000= \\
-14000\end{array}$ & $\begin{array}{c}28000-14000= \\
14000\end{array}$ & 0 \\
\hline
\end{tabular}

Step two: scientifically set the future global emissions target during T1-T2 and calculate each country's NEA balance during T1-T2

The global per capita emissions entitlement during T1-T2 is 50 units of carbon dioxide. The total global accumulated emissions by $\mathrm{T} 2$ will reach 72000 units of carbon dioxide. For simplicity, we do not take into account the removal of greenhouse gases in the short run in this hypothetical example. According to the per capita principle, the allocation of emission entitlements and balances for each country can be calculated (Table 17.3). The total balance for each country is the addition of its balance during $\mathrm{T} 0-\mathrm{T} 1$ and that in T1-T2. The balance exactly represents each country's responsibility for emissions reduction (or entitlements to emit).

\section{Table 17.3 National emissions account during T1-T2}

\begin{tabular}{l|c|c|c}
\hline & Country A & Country B & World \\
\hline Emission entitlements & $50 \times 200=10000$ & $50 \times 400=20000$ & 30000 \\
\hline Real emissions & Yet to happen & Yet to happen & $\begin{array}{c}\text { Yet to } \\
\text { happen }\end{array}$ \\
\hline Traded emissions & Yet to happen & Yet to happen & $\begin{array}{c}\text { Yet to } \\
\text { happen }\end{array}$ \\
\hline Balance at T1 & $\begin{array}{c}-14000+10000= \\
-4000\end{array}$ & $\begin{array}{c}14000+20000= \\
34000\end{array}$ & 30000 \\
\hline
\end{tabular}




\section{The findings from the demonstration}

First, it is misleading to simply compare the current annual emissions of different countries at $\mathrm{T} 1$. In the example, the current annual emissions of countries A and B at T1 are both 400 units, but their per capita real emissions are very different. The global per capita emission is 1.33 units, while the per capita emission of country B is 1 - far lower than the 2 units of country A. Without considering historical emissions, country A overemits 0.67 unit per person per annum, while country B still has 0.33 unit to reach the global average per capita level.

Second, it is misleading to simply compare per capita annual emissions of different countries. To show this, we adjust the current annual emissions of country B in Table 17.1 from 400 to 800, then the current per capita annual emissions of the two countries are equal to 2 units. Since the historical emission of country A is higher than that of country B, however, country A has infringed 14000 units of emission entitlements from country B.

Third, once the emission entitlements of all countries are clearly defined, the real emissions of each country can no longer be used as the measurement for their contributions to global emissions reduction. For instance, in theory, country A can develop all zero-emission service industries and import emissions-embedded goods from country B, while country B, in addition to its own emissions quotas, buys all emissions quotas of country A to develop emissions-intensive industries and exports emissions-embedded manufactured goods to country A. In this case, all global emissions are done by country B, and country A emits zero. This does not mean, however, that country A has made a bigger contribution to global emissions reduction; both countries have made the same contribution. Also, to simply pursue a low-carbon economy is misleading. In this case, country $\mathrm{A}$ is a zeroemission economy while country B is an emission-intensive economy, but the welfare of the two countries could be the same.

Fourth, the reason why country A should take more responsibility for climate change is not because it is richer than country B (that is, the so-called different capacities) or because country B has a 'right to development', but because country B bears the harm imposed by the extra emissions of country A, represented by its deficit of -14000 units. This means that the rationale behind the NEA-based solution is substantially different from those emphasising the capacity difference. ${ }^{3}$ Meanwhile, how much responsibility a country should take for climate change is 
irrelevant to whether or not it is large. A country cannot be required to take more responsibility just because it is big in size. If a large developing country was not a single country but an economic bloc consisting of 30 poor countries, no-one would require the 30 poor countries to reduce their emissions. In reality, however, there is no substantial difference between the two cases.

\section{The advantages of the NEA-based solution}

First, this solution is an upgraded version of the Kyoto Protocol: it maintains its advantages but overcomes its flaws.

- It offers full coverage: all countries can be covered. To classify the countries into industrialised and developing countries is then no longer necessary in the proposal. The problem of carbon leakage is also solved once all countries are covered by the new protocol. In practice, it can cover the major emitters first, and then extend further to cover the minor emitters later.

- It offers effectiveness: the global reduction target is built into the proposal, since the global aggregate emission amount in the future is scientifically determined and then allocated among all countries. Also, an accumulated emissions target replaces the percentage target in the Kyoto Protocol.

- The additionality problem of the CDM is overcome. A CDM project will increase the balance of the investing country and accordingly reduce the balance of the host country side-by-side. The NEA approach can therefore not only overcome the additionality problem, it can further extend the CDM to a two-way mechanism-that is, the firms in developing countries can also invest in emissions-reduction projects in industrialised countries.

Second, the vague 'common but differentiated responsibilities' are clearly defined in the proposal. An NEA is an effective tool by which to measure and manage global emissions reductions. Each country's emissions balance exactly represents its responsibility for emissions reduction.

Third, once each country's emissions account is established, emissions reduction becomes a self-interested behaviour: the more a country reduces, the more quotas it can sell or the less quotas it needs to buy. A strong incentive mechanism for global emissions reduction is therefore established. 
Fourth, the NEA approach is compatible with various existing international collaborative mechanisms and domestic reduction approaches. The various approaches can compete with each other in the NEA framework.

Fifth, for the countries that are not yet covered by the Kyoto Protocol or that have failed to meet their commitments, their contribution to and responsibilities for emissions reduction are clearly measured and recorded by their NEAs.

\section{Discussions}

\section{Contraction and convergence}

Since the principle of 'contraction and convergence' was first proposed by the Global Commons Institute in 2000, it has been widely embraced by some industrialised countries. Under contraction and convergence, each country will start out with emission entitlements equal to its current real emissions levels, and then, over time, converge to equal its per capita entitlements, while the overall global budget contracts to accommodate the emissions reduction objective. The problem of convergence is that now that it recognises the per capita principle as a fair principle in the allocation of emission entitlements, the principle should be applied from T0, rather than as late as the 'converged point' in the future (T2). 'Real emissions' is a different concept to 'emissions entitlement'. A country's high/low per capita real emissions cannot justify its high/low emission entitlements. In the process of convergence, the rights and interests of country B are really infringed by country A. In the NEA-based solution, the concept of convergence can still be incorporated, but it now merely means 'convergence of real emissions' rather than 'convergence of emission entitlements'. Each country's gaps between its emission entitlements and real emissions need to be balanced by the traded emissions quotas.

\section{Common but differentiated responsibilities}

The principle of 'common but differentiated responsibilities' is a critical one for protecting the rights of developing countries with regard to climate change, but is still not sufficient. Under the existing framework of the Kyoto Protocol, developing countries are not required to reduce their emissions. This makes it look like only the industrialised countries are making a contribution to global emissions reductions, while the developing 
countries are not. Nonetheless, according to their NEA balances, country A, with 14000 deficits, should reduce much more, and country B, with 34000 surplus units, is entitled to claim more compensation from country A. Because the differentiated responsibilities are not clearly defined, however, both the greater responsibilities of country A and the rights of country B cannot be seen clearly in the existing Kyoto framework.

\section{Global public fund on climate change}

A focus of international climate negotiations is how industrialised countries can transfer technologies and funds to developing countries for mitigation and adaptation. The proposal for a global public fund for emissions reduction has been widely discussed (Bhagwati 2006; Garnaut 2008:Ch.10). The rationale for why industrialised countries should provide technologies and funds to developing countries is mainly because of the former's historical emissions. Under the unclear differentiated responsibilities, the establishment of such a global fund could be deemed as the resolution of the historical problem - and all countries will be at the same level on emissions reductions. Nonetheless, this rough calculation is avoided in the NEA-based solution. For instance, a country's emissions deficit might be reduced by only 30 per cent after a country has made a big contribution to the global public fund.

\section{The issue of embedded emissions}

The issue of embedded emissions has also been widely discussed. In the NEA-based global solution, embedded emissions in different situations have different welfare effects. First, during the historical period of T0-T1, since emission entitlements were not clearly defined and emission costs were not reflected in the price of traded goods, the embedded emissions, in theory, should be treated as the real emissions of the importing countrythough it is almost infeasible to be measured in practice. Second, since each country's emission entitlements during T1-T2 are clearly allocated and the emission costs will be reflected in the price of traded goods, it is not meaningful to take into account embedded emissions in the productionapproach measurement. Third, if, however, some countries are not covered by the international emissions reduction protocol, the countries not covered will impact on the export industries of the countries producing emissions-embedded goods. Carbon leakage to the countries not covered is inevitable. The solution to this problem is not to relax the emissions reduction targets of the home countries, but to ensure all countries are covered by the international agreement. 


\section{Is global warming a market failure?}

Global warming is widely seen as a market failure (for example, Stern 2007). This is somewhat misleading. The condition for a market to function is well-defined property rights. Without emissions rights being clearly defined, we cannot expect the market to work on global warming. Defining emissions rights is, however, the job of government. Greenhouse gases are a global public good/hazard. That means we need a global 'government' to provide the public service of defining and enforcing each country's emission entitlements. In an era of globalisation, we need to establish effective global governance, rather than relying on government intervention to solve climate change.

\section{What does the per capita principle mean to large developing countries?}

Many people might think that the populous developing countries, such as China, will benefit greatly from the per capita principle; in reality, they will not. The per capita principle merely allocates a low carbon growth model to China, since, according to the principle, China's accumulated per capita emissions can reach only the world average level in the future - much lower than the current high level of real emissions in the industrialised countries. It is impossible for China to adopt a business-as-usual growth model in the future as the industrialised countries did previously. China will be under huge pressure to lower its emissions according to the per capita principle.

\section{Conclusion}

Based on the principle that no country has the right to impose extra external harm on any other country without compensation, this chapter has developed a theoretical framework for how to allocate GHG emission entitlements for each country. The historical and future initial emission entitlements should be allocated according to the per capita principle. A country's national emissions account (NEA) can be established according to its emission entitlements, real emissions and traded emissions. The balance of the NEA of each country exactly represents its responsibility for emissions reduction. The optimal global allocation of real emissions can be achieved through the transaction of initial emission entitlements. The embedded emissions during T0-Tl should be taken into account when 
measuring the real emissions of each country, while it is not necessary to be take into account those during T1-T2. The NEA-based global solution aims to cover all countries. In order to improve its effectiveness, however, it might first cover the major emitters and then extend to other countries once they are ready.

The proposed NEA approach is still an in-principle framework and many details are yet to be sorted out. For instance, how and from what point should the historical emissions of each country be measured? How can the future global emissions targets be set scientifically? What sorts of international and national institutional infrastructure are required for the NEA approach? For how long should the emissions deficits of the industrialised countries be eliminated? How can relevant systems of international trading, supervision and implementation be designed? Although the choice of which kind of post-Kyoto protocol to adopt is more a political decision than a purely academic issue, the most essential requirement in order for the protocol to be widely accepted is that it should be built on justification, rather than being decided by arm-twisting. The NEA approach is such a solution, with no bias to any particular countries or interests.

At present, most of the literature on climate change presumes that emissions reduction will conflict with economic development in the short term. With rapid technological innovations in renewable energy, however, there appears to be great potential for a low-carbon economic development model to replace the traditional high emissions growth model. The technological innovation must be driven mainly by market incentives, rather than by government intervention (Romer 1990). The NEA approach provides such an incentive. If the emission entitlements of all countries can be clearly defined and strictly enforced then the market can function well and emissions reduction will become a self-interested behaviour. In the long run, GHG emissions reduction will bring prosperity and sustainability to human society.

\section{Acknowledgments}

This chapter is an outcome of the Development Research Centre project Fighting Against Global Climate Change, headed by Yutai Zhang. Project team leader: Shijin Liu. Draft author: Yongsheng Zhang (<zys@drc. gov.cn $>$ ). Revised and finalised by: Shijin Liu. Discussants: Junkuo Zhang, Hongchun Zhou, Peilin Liu, Zhenyu Wu and Anbo Xiang. The 
authors thank the valuable comments, suggestions and criticisms from Shiro Armstrong, Peter Drysdale, Steven Howes, Frank Jotzo, Warwick McKibbin, Yew-Kwang Ng, Ligang Song and Shuntian Yao. The authors are solely responsible for the errors.

\section{References}

Aldy, J. E., Barrett, S. and Stavins, R. N. (eds) 2007, 13+1: a comparision of global climate change policy architectures, Discussion Paper, dp-03-26, Resources for the Future, Washington, DC.

Aldy, J. E. and Stavins, R. N. (eds) 2007, Architectures for Agreement: Addressing global climate change in the post-Kyoto world, Cambridge University Press, New York.

Bhagwati, J. 2006, 'A global warming fund could succeed where Kyoto failed', Financial Times, 16 August 2006.

Cheung, S. 1970, 'The structure of a contract and the theory of a nonexclusive resource', Journal of Law and Economics, vol. 13, pp. 49-70.

Coase, R. 1960, 'The problem of social cost', Journal of Law and Economics, vol. 3, pp. 1-44.

European Commission (EC) 2008, Questions and answers on the commission's proposal to revise the EU emissions trading system, MEMO/08/35, 23 January, European Commission, Brussels.

Frankel, J. 2007, 'Formulas for quantitative emissions targets', in J. E. Aldy and R. N. Stavins (eds), Architectures for Agreement: Addressing global climate change in the post-Kyoto world, Cambridge University Press, New York.

Garnaut, R. 2008, The Garnaut Climate Change Review, Cambridge University Press, Melbourne.

Grossman, S. and Hart, O. 1986, 'The costs and benefits of ownership: a theory of vertical and lateral integration', Journal of Political Economy, vol. 94, pp. 691-719.

Hart, O. and Moore, B. 1990, 'Property rights and the nature of the firm', Journal of Political Economy, vol. 98, pp. 1119-58.

Hardin, G. 1968, 'The tragedy of the commons', Science, vol. 162, pp. 1243-8. 
Solomon, S., Qin, D., Manning, M., Chen, Z., Marquis, M., Avery, K. B., Tignor, M. and Miller, H. L. (eds) 2007, Climate Change 2007: The physical science basis. Contribution of Working Group I to the fourth assessment report of the IPCC, Intergovernmental Panel on Climate Change, Cambridge University Press, Cambridge and New York.

Metz, B., Davidson, O. R., Bosch, P. R., Dave, R. and Meyer, L. A. (eds) 2007, Climate Change 2007: Mitigation of climate change. Contribution of Working Group III to the fourth assessment report of the IPCC, Intergovernmental Panel on Climate Change, Cambridge University Press, Cambridge.

Nordhause, W. 2006, 'After Kyoto: alternative mechanism to control global warming', American Economic Review, May.

2008, The Challenge of Global Warming: Economic models and environmental policy, Yale University Press, New Haven, Conn.

Pew Center on Climate Change 2005, International Climate Efforts Beyond 2012: Report of climate dialogue at Pocantico, Pew Center on Climate Change, Arlington, Va.

Romer, P. 1990, 'Endogenous technological change', Journal of Political Economy, vol. 98, S71-102.

Sagar and Kandlikar 1997, 'Knowledge, rhetoric and power: international politics of climate change', Economic and Political Weekly, vol. 32, no. 49 (6-12 December), pp. 3139-48.

Stern, N. 2007, The Economics of Climate Change: The Stern review, Cambridge University Press, Cambridge.

Stiglitz, J. 2006, 'A new agenda for global warming', Economist's Voice, The Berkeley Electronic Press, University of California, Berkeley, $<$ www.bepress.com/ev $>$

United Nations Framework Convention on Climate Change (UNFCCC) 2007, Report of the Conference of the Parties on its Thirteenth Session, held in Bali from 3 to 15 December 2007. Addendum, Part Two: Action taken by the conference of the parties at its thirteenth session, FCCC/ CP/2007/6/Add.1, United Nations Framework Convention on Climate Change, Bonn, Germany.

Weitzman, M. L. 1974, 'Prices vs. quantities', Review of Economic Studies, vol. 41, no. 4, pp. 477-91. 


\section{Endnotes}

1. A major disagreement between industrialised and developing countries centres on which year to start T0 from. This question is open in the proposal, as long as 1) the starting year can be justified, and 2) someone can be held responsible for all the existing emissions in the atmosphere.

2. In reality, the harm different people in different regions suffered cannot be 100 per cent equal, but for simplicity, the assumption of equal harm is acceptable.

3. The NEA-based solution is different from those associating each country's responsibility with its income level (for instance, Pew Center on Climate Change 2005; Frankel 2007; UNFCCC 2007). 